\title{
STRATEGI PENGEMBANGAN INSTALASI FARMASI RSUD DATOE BINANGKANG DI KABUPATEN BOLAANG MONGONDOW MENGGUNAKAN ANALISIS SWOT
}

\section{DEVELOPMENT STRATEGY OF PHARMACY INSTALLATION USES SWOT ANALYSIS AT RSUD DATOE BINANGKANG IN BOLAANG MONGONDOW REGENCY}

\author{
Wahyu Mila Ardiany ${ }^{1)^{*}}$, Gayatri Citraningtyas ${ }^{1)}$, Deby A. Mpila ${ }^{1)}$ \\ ${ }^{1)}$ Program Studi Farmasi FMIPA UNSRAT Manado, 95115 \\ *milaardiany@gmail.com
}

\begin{abstract}
Pharmacy Installation plays a role in providing quality health services in Hospitals, it was necessary to have an analysis of the development strategy of the Pharmacy Installation at RSUD Datoe Binangkang in accordance with internal and external conditions. This studied aims to determine the development strategy in the Pharmacy Installation of RSUD Datoe Binangkang used SWOT analysis. The methods used in this research are quantitative and qualitative methods with descriptive research designs used questionnaires, interviews and observations. The results showed that the Pharmacy Installation of RSUD Datoe Binangkang was at coordinates point $x=1,048$ and $y=0,779$. The Pharmacy Installation of RSUD Datoe Binangkang was at the first quadrant and it can be said to be strong and likely. Conclusions gained that the strategy used was an aggressive strategy.
\end{abstract}

Keywords: Development strategy, Pharmacy Installation, SWOT

\begin{abstract}
ABSTRAK
Instalasi Farmasi berperan dalam memberikan pelayanan kesehatan yang berkualitas di Rumah Sakit, sehingga diperlukan adanya analisis strategi pengembangan Instalasi Farmasi di RSUD Datoe Binangkang yang sesuai dengan kondisi internal dan eksternal. Penelitian ini bertujuan untuk menentukan strategi pengembangan di Instalasi Farmasi RSUD Datoe Binangkang dengan menggunakan analisis SWOT. Metode yang digunakan dalam penelitian ini merupakan metode kuantitatif dan kualitatif dengan rancangan penelitian deskriptif menggunakan kuisioner, wawancara dan observasi. Hasil penelitian menunjukan bahwa Instalasi Farmasi RSUD Datoe Binangkang berada pada titik koordinat $\mathrm{x}=1,048$ dan $\mathrm{y}=0,779$. Instalasi Farmasi RSUD Datoe Binangkang berada pada kuadran pertama sehingga dapat dikatakan kuat dan berpeluang. Kesimpulan yang didapat bahwa strategi yang digunakan adalah strategi agresif.
\end{abstract}

Kata kunci: Strategi pengembangan, Instalasi Farmasi, SWOT 


\section{PENDAHULUAN}

Standar pelayanan Instalasi Farmasi Rumah Sakit menyatakan bahwa pelayanan farmasi tak terpisahkan dari sistem pelayanan kesehatan Rumah Sakit yang utuh dan berorientasi kepada pelayanan pasien, penyediaan obat yang bermutu, serta pelayanan farmasi klinik yang terjangkau bagi seluruh lapisan masyarakat. Instalasi Farmasi Rumah Sakit adalah unit pelaksana fungsional yang menyelenggarakan seluruh kegiatan pelayanan kefarmasian di Rumah Sakit (Depkes RI, 2009).

Instalasi Farmasi berperan dalam kelancaran pelayanan kesehatan juga sebagai sumber pendapatan terbesar di Rumah Sakit. Maka strategi pengembangan Instalasi Farmasi Rumah Sakit (IFRS) perlu dilakukan dalam menghadapi persaingan dengan Rumah Sakit lain (Siregar, 2003). SWOT adalah singkatan dari, Strenght atau kekuatan, Weakness atau kelemahan, Oppurtunity atau peluang, dan Threat atau ancaman. SWOT ini biasa digunakan untuk menganalisis suatu kondisi dimana akan dibuat sebuah rencana untuk melakukan suatu program kerja (Buchari Alma, 2008).

Saat ini, Instalasi Farmasi RSUD Datoe Binangkang sedang berupaya untuk meningkatkan mutu pelayanan. Oleh sebab itu, perlu dilakukan evaluasi pengembangan Instalasi Farmasi agar dapat meningkatkan mutu pelayanan serta mengetahui aspek mana saja yang masih perlu ditingkatkan. Berdasarkan aspek lingkungan tersebut maka dapat digunakan pendekatan menggunakan analisis SWOT. Berdasarkan uraian latar belakang diatas peneliti merasa perlu adanya penelitian tentang strategi pengembangan Instalasi Farmasi RSUD Datoe Binangkang menggunakan analisis SWOT di Kabupaten Bolaang Mongondow.

Tujuan penelitian ini adalah untuk menentukan strategi pengembangan di Instalasi Farmasi RSUD Datoe Binangkang dengan menggunakan analisis SWOT.

\section{METODOLOGI PENELITIAN}

\section{Waktu dan Tempat Peneliatian}

Penelitian ini dilaksanakan pada bulan Januari - Juli 2020 di RSUD Datoe Binangkang Kabupaten Bolaang Mongondow.

\section{Jenis dan Rancangan Penelitian}

Penelitian ini merupakan jenis penelitian non eksperimental dengan rancangan deskriptif menggunakan metode kuantitatif dan kualitatif. Data kuantitatif diperoleh melalui kuisioner sedangkan data kualitatif diperoleh melalui wawancara dan observasi langsung.

\section{Alat dan Bahan \\ Alat}

Alat yang digunakan dalam penelitian ini adalah alat tulis menulis, lembar kuisioner, alat perekam suara dan kamera untuk dokumentasi.

\section{Bahan}

Bahan yang digunakan dalam penelitian ini terdiri dari dua data yaitu:

1. Data Primer

Data primer yang digunakan dalam penelitian ini diperoleh dari kuisioner yang diisi oleh responden, observasi dan wawancara kepada karyawan juga kepala IFRS.

2. Data Sekunder

Data sekunder yang digunakan dalam penelitian ini adalah literatur-literatur, jurnal dan artikel penelitian yang mendukung data primer.

\section{Populasi Penelitian}

Populasi dalam penelitian ini adalah kepala IFRS, 12 karyawan IFRS serta seluruh pasien atau keluarga pasien rawat inap yang menebus obat di Instalasi Farmasi.

\section{Sampel Penelitian}

Sampel yang digunakan dalam penelitian ini adalah pasien atau keluarga pasien rawat inap yang menebus obat di 
Instalasi Farmasi RSUD Datoe Binangkang yang memenuhi kriteria inklusi dan eksklusi sebagai berikut:

1. Kriteria Inklusi

a. Bersedia berpartisipasi dengan mengisi kuisioner yang diberikan.

b. Pasien atau keluarga pasien rawat inap yang lebih dari satu kali menebus obat di Instalasi Farmasi RSUD Datoe Binangkang.

2. Kriteria Eksklusi

a. Pasien atau keluarga pasien rawat inap yang baru pertama kali menebus obat di Instalasi Farmasi RSUD Datoe Binangkang.

Besaran sampel pada penelitian ini diukur menggunakan Rumus Slovin (Sugiyono, 2011) adalah sebagai berikut:

$$
n=\frac{N}{1+N e^{2}}
$$

Keterangan:

$\mathrm{n}=$ Jumlah sampel yang diambil

$\mathrm{N}=$ Jumlah populasi

$\mathrm{e}=$ Persentase kesalahan sampel, $\mathrm{e}=0,05$ $(5 \%)$

Berdasarkan perhitungan diatas maka minimal sampel yang digunakan dalam penelitian ini berjumlah 124 responden.

\section{Analisis Data}

Kuisioner yang digunakan mengacu pada kuisioner servqual serta pembobotan menggunakan skala likert. Selanjutnya dihitung analisis gap antara skor kinerja dengan skor harapan. Hasil olah data disajikan dalam bentuk tabel, kemudian dijumlahkan serta dihitung rata-rata nilai persentasenya. Analisis SWOT dilakukan dengan menentukan faktor-faktor internal dan eksternal, kemudian menentukan kudran berdasarkan jumlah skor dari internal factor analysis summary (IFAS) dan external factor analysis summary (EFAS). Terdapat empat kuadran, dimana masing-masing kuadran memiliki alternatif-alternatif strategi, yaitu kuadran 1 (strategi agresif), kuadran 2 (strategi diversifikasi), kuadran 3 (strategi turn around) dan kuadran 4 (strategi defensif). Selanjutnya disusun matriks SWOT serta menentukan strategi alternatif berdasarkan analisis SWOT sesuai letak kuadran.

\section{HASIL DAN PEMBAHASAN Karakteristik Responden}

Karakteristik responden pada penelitian ini dibagi kedalam 3 kelompok yaitu jenis kelamin, umur dan pendidikan terakhir.

Tabel 1. Karakteristik Responden

\begin{tabular}{lll}
\hline Karakteristik & \multicolumn{2}{l}{ Total } \\
\cline { 2 - 3 } & $\mathbf{n}$ & $\mathbf{( \% )}$ \\
\hline Jenis Kelamin & & \\
Laki-laki & 32 & 25,8 \\
Perempuan & 92 & 74,2 \\
\hline
\end{tabular}

\begin{tabular}{lll}
\hline $\begin{array}{l}\text { Usia } \quad \text { (Depkes, } \\
\text { 2009) }\end{array}$ & & \\
17 - 25 Tahun & 28 & 22,6 \\
26 - 35 Tahun & 44 & 35,5 \\
36 - 45 Tahun & 29 & 23,5 \\
46 - 56 Tahun & 11 & 8,8 \\
56 - 65 Tahun & 11 & 8,8 \\
$>$ 65 Tahun & 1 & 0,8 \\
\hline Pendidikan & & \\
SD & 22 & 17,7 \\
SLTP & 23 & 18,5 \\
SLTA & 59 & 47,6 \\
Sarjana & 20 & 16,2 \\
\hline Keterang & &
\end{tabular}

Keterangan:

$\mathrm{n}=$ Jumlah Pasien/keluarga pasien

$\%=$ Persentase

Hasil penelitian karakteristik jenis kelamin responden terbanyak didominasi oleh kelompok perempuan yaitu sebanyak $74,2 \%$. Menurut Notoatmodjo (2010) pengguna pelayanan kesehatan oleh wanita lebih tinggi dibandingkan dengan laki-laki. Hal tersebut dikarenakan wanita mempunyai kejadian dan risiko penyakit yang lebih besar dibandingkan dengan laki-laki.

Responden terbanyak berada pada rentang usia 26-35 tahun yaitu sebanyak $35,5 \%$. Usia berpengaruh terhadap pola pikir seseorang, hal ini di buktikan dengan hasil 
penelitian Sulo, et al. (2019) menyatakan bahwa persepsi seseorang terhadap suatu pelayanan terbangun salah satunya berdasarkan pada pengalamannya dimasa lalu.

Menurut Notoatmodjo (2005)

menyatakan bahwa tingkat pendidikan merupakan salah satu faktor yang mempengaruhi harapan dan persepsi pasien terhadap pelayanan kesehatan.

\section{Analisis Gap Lima Dimensi Kualitas Pelayanan}

Gap (kesenjangan) dari kelima dimensi menggambarkan selisih antara

Tabel 2. Analisis Gap Lima Dimensi

\begin{tabular}{lllll}
\hline No. & Dimensi kualitas pelayanan & Kinerja & Harapan & Gap \\
\hline 1. & Tangible & 3,26 & 3,59 & $-0,33$ \\
2. & Reliability & 3,49 & 3,71 & $-0,22$ \\
3. & Assurance & 3,50 & 3,64 & $-0,14$ \\
4. & Emphaty & 3,57 & 3,47 & $-0,01$ \\
5. & Responsiveness & 3,59 & 3,73 & $-0,14$ \\
\hline
\end{tabular}

Tabel diatas menunjukan selisih gap antara kinerja dan harapan. Gap terbesar berada pada dimensi tangible yaitu sebesar -0,33 sedangkan gap terkecil berada pada dimensi emphaty yaitu sebesar -0,01 sehingga menyebabkan belum terpenuhinya kepuasan pasien. Penelitian Sulo, et al. (2019) menyatakan bahwa indeks kepuasan secara keseluruhan maupun setiap dimensi menunjukan nilai negatif yang berarti pasien masih merasa belum puas terhadap pelayanan di Instalasi Farmasi Rumah Sakit.

\section{Analisis SWOT}

Analisis SWOT digunakan untuk merumuskan strategi dengan mengidentifikasi faktor-faktor internal maupun eksternal secara sistematis. Berikut ini merupakan rangkuman dari hasil pembobotan dan peratingan yang dapat dilihat pada tabel 3 dan 4 .

Kekuatan yang dimiliki Instalasi Farmasi RSUD Datoe Binangkang, yaitu merupakan satu-satunya Rumah Sakit di daerah tersebut, memiliki standar operasional pelayanan, sebagai rumah sakit rujukan dan kinerja Instalasi Farmasi RSUD Dataoe Binangkang dengan harapan pasien/keluarga pasien rawat inap terhadap kualitas pelayanan. Menurut Al Borie (2013) idealnya nilai gap antara kinerja dan harapan adalah nol, artinya kinerja yang diberikan telah sesuai dengan harapan pasien. Angka negatif menunjukkan adanya harapan pasien yang belum terpenuhi, sedangkan angka positif menunjukkan harapan pasien telah terpenuhi. Hasil analisis gap lima dimensi dapat dilihat pada tebel 2 . tersedianya 12 poli klinik dengan dokter spesialis di setiap polinya. Sedangkan kelemahan dari Instalasi Farmasi RSUD Datoe Binangkang, yaitu lokasi RSUD kurang strategis, sarana \& pra sarana yang belum optimal, letak IFRS jauh dari bangsal dan kurang terciptanya komunikasi antara pasien dengan karyawan farmasi.

Peluang yang dimiliki oleh Instalasi Farmasi RSUD Datoe Binangkang adalah dukungan pemerintah daerah, bekerjasama dengan BPJS dan menerapkan kebijakan satu pintu. Selain itu, ada juga ancaman bagi Instalasi Farmasi RSUD Datoe Binangkang yaitu mengikuti perkembangan IPTEK di era globalisasi, kualitas sumber daya manusia dalam persaingan era globalisasi, adanya apotek pelengkap dan tuntutan customer terhadap pelayanan informasi obat. 
Tabel 3. Hasil Internal Factor Analysis Summary

\begin{tabular}{|c|c|c|c|}
\hline Faktor Kekuatan & Bobot & Rating & Skor \\
\hline RSUD Datoe Binangkang merupakan satu-satunya Rumah & 0,181 & 4 & 0,727 \\
\hline Adanya standar oprasional pelayanan & 0,136 & 3 & 0,409 \\
\hline Sebagai rumah sakit rujukan & 0,136 & 3 & 0,409 \\
\hline $\begin{array}{l}\text { Tersedianya } 12 \text { poli klinik dengan dokter spesialis di setiap } \\
\text { polinya }\end{array}$ & 0,136 & 3 & 0,409 \\
\hline Jumlah & & 13 & 1,954 \\
\hline \multicolumn{4}{|l|}{ Faktor Kelemahan } \\
\hline Lokasi RSUD kurang strategis & 0,091 & 2 & 0,181 \\
\hline Sarana dan pra sarana yang belum optimal & 0,091 & 2 & 0,181 \\
\hline Letak IFRS jauh dari bangsal & 0,136 & 2 & 0,272 \\
\hline $\begin{array}{l}\text { Kurang terciptanya komunikasi antara pasien dengan karyawan } \\
\text { farmasi }\end{array}$ & 0,091 & 3 & 0,272 \\
\hline Jumlah & & 9 & 0,906 \\
\hline Total & $\mathbf{1 , 0 0}$ & & \\
\hline
\end{tabular}

Tabel 4. Hasil External Factor Analysis Summary

\begin{tabular}{|c|c|c|c|}
\hline \multicolumn{2}{|l|}{ Faktor Peluang } & Rating & Skor \\
\hline \multicolumn{2}{|l|}{ Dukungan pemerintah daerah } & 0,222 & 0,889 \\
\hline \multicolumn{2}{|l|}{ RSUD Sudah bekerjasama dengan BPJS } & 0,111 & 0,333 \\
\hline \multicolumn{2}{|l|}{ Kebijakan satu pintu } & 0,167 & 0,667 \\
\hline \multicolumn{2}{|l|}{ Jumlah } & 11 & $\mathbf{1 , 8 8 9}$ \\
\hline \multicolumn{4}{|l|}{ Faktor Ancaman } \\
\hline \multicolumn{2}{|l|}{ Mengikuti perkembangan IPTEK di era globalisasi } & 0,111 & 0,222 \\
\hline \multicolumn{2}{|c|}{ Kualitas sumber daya manusia dalam persaingan era globalisasi } & 0,111 & 0,222 \\
\hline \multicolumn{2}{|l|}{ Adanya apotek pelengkap di dalam RSUD } & 0,111 & 0,333 \\
\hline \multicolumn{2}{|l|}{ Tuntutan customer terhadap kelengkapan obat } & 0,167 & 0,333 \\
\hline \multicolumn{2}{|l|}{ Jumlah } & 9 & $\mathbf{1 , 1 1}$ \\
\hline \multicolumn{2}{|l|}{ Total } & $\mathbf{1 , 0 0}$ & \\
\hline \begin{tabular}{l}
\multicolumn{4}{c}{ Hasil analisis kekuatan dan kelemahan } \\
pada Instalasi Farmasi RSUD \\
Binangkang memperoleh angka positif \\
sebesar 1,048. Hal ini menunjukan bahwa \\
kekuatan Instalasi Farmasi RSUD Datoe \\
Binangkang masih lebih besar dari \\
kelemahannya. Selain itu, untuk hasil analisis \\
peluang dan ancaman pada Instalasi Farmasi \\
RSUD Datoe Binangkang juga memperoleh \\
angka positif sebesar 0,779. Hal tersebut \\
berarti peluang Instalasi Farmasi RSUD
\end{tabular} & \multicolumn{3}{|c|}{$\begin{array}{l}\text { Instalasi Farmasi RSUD Datoe Binangkang } \\
\text { adalah menggunakan kekuatan untuk } \\
\text { memanfaatkan peluang jangka panjang, yaitu } \\
\text { dengan peningkatan kualitas dan kuantitas } \\
\text { sumber daya manusia, mengoptimalkan } \\
\text { pasien BPJS dan meningkatkan pelayanan } \\
\text { farmasi yang lebih fokus pada kepuasan } \\
\text { pasien. Analisis tersebut dirangkum secara } \\
\text { singkat dalam matrik SWOT yang dapat } \\
\text { dilihat pada tabel 5. }\end{array}$} \\
\hline
\end{tabular}

Datoe Binangkang masih lebih besar dari ancaman yang ada. 
Tabel 5. Matrik SWOT

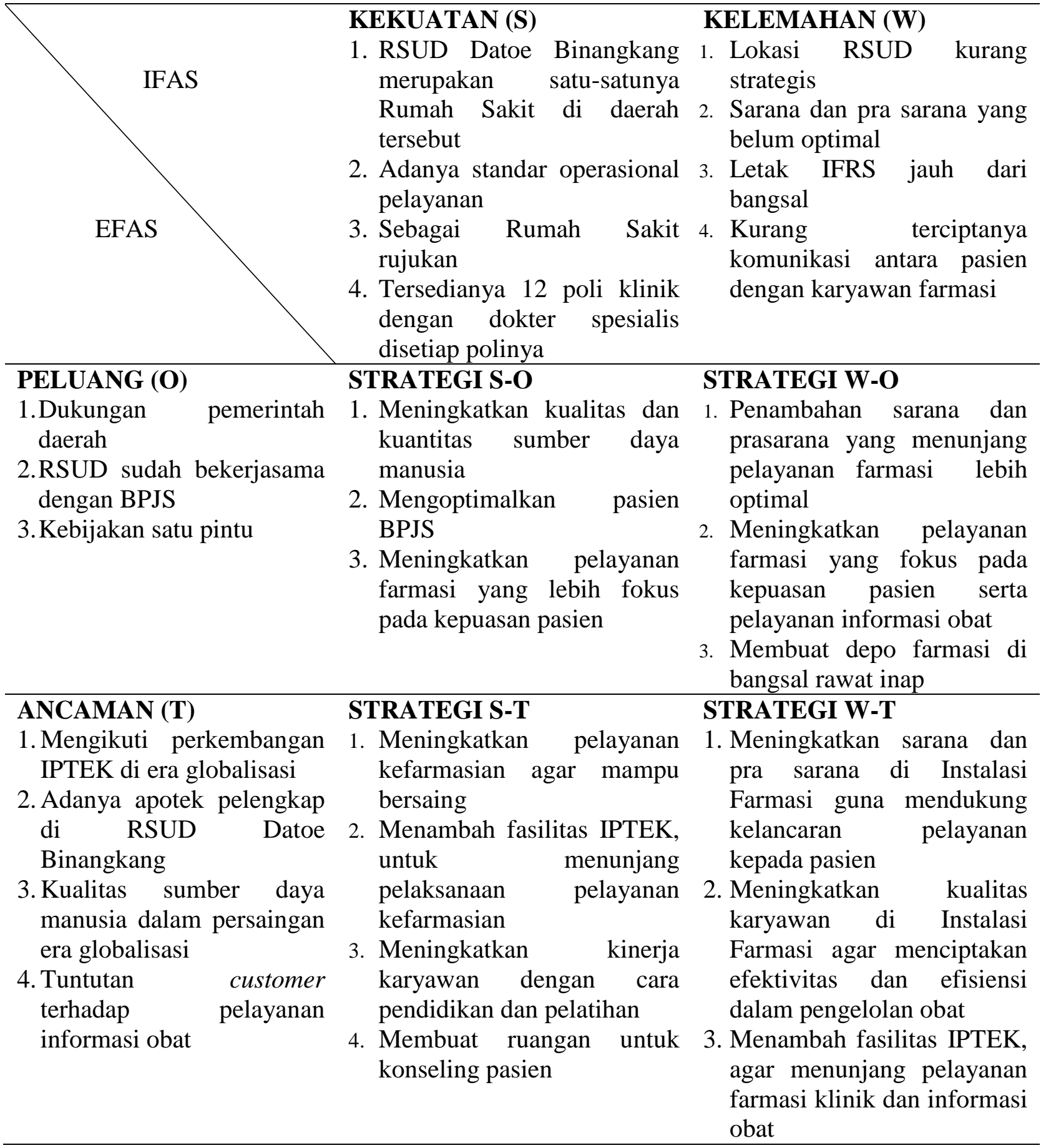

\section{KESIMPULAN}

Instalasi Farmasi RSUD Datoe Binangkang berdasarkan faktor internal dan eksternal berada pada posisi kuadran pertama, yang berarti kekuatan yang dimiliki Instalasi Farmasi RSUD Datoe Binangkang masih lebih besar daripada kelemahan serta peluang yang dimiliki lebih besar dari ancaman yang ada. Hal ini menunjukan bahwa Instalasi Farmasi RSUD Datoe Binangkang berada pada posisi kuat dan peluang. Sehingga strategi yang cocok digunakan adalah strategi agresif menggunakan alternatif seperti peningkatkan kemampuan dalam melaksanakan kegiatan kefarmasian, 
penambahan fasilitas agar pelayanan farmasi lebih optimal, peningkatan kualitas dan kuantitas SDM, pengoptimalan pasien BPJS, dan fokus pada customer satisfaction.

\section{SARAN}

Bagi peneliti lain yang tertarik melakukan penelitian lebih lanjut tentang strategi pengembangan Instalasi Farmasi RSUD Datoe Binangkang Kabupaten Bolaang Mongondow untuk melakukan penelitian dengan menggunakan metode lain seperti matriks Boston Consuling Group (BCG), matriks Strategic Position and Action Evaluation (SPACE), matriks Eksternal Factor Evaluation (EFE), matriks Internal Factor Evaluation (IFE) dan matriks Competition Profile (CP).

\section{DAFTAR PUSTAKA}

Al Borie., Damanhouri A.M. 2013. Patient's statisfaction of service quality in Saud hospital: a servqual analysis. International Journal Of Health Care Quality Assurance 26(1): 20-30.

Buchari Alma. 2008. Manajemen Pemasaran dan Pemasaran Jasa. CV Alfabeta, Bandung.

Depkes RI. 2004. Keputusan Menteri Kesehatan Republik Indonesia Nomor: 1197/Menkes/SK/X/2004 Tentang Standar Pelayanan Farmasi Di Rumah Sakit. Direktorat Jendral Pelayanan
Kefarmasian Dan Alat Kesehatan. Departemen Kesehatan Republik Indonesia, Jakarta.

Depkes RI. 2009. Klasifikasi Umur Menurut Kategori. Ditjen Yankes, Jakarta.

Depkes RI. 2009. Undang-Undang Republik Indonesia Nomer 44 Tentang Rumah Sakit. Departemen Kesehatan Republik Indonesia, Jakarta.

Notoatmodjo, S. 2005. Metodologi Penelitian Kesehatan. Rineka Cipta, Jakarta.

Notoatmodjo, S. 2010. Pendidikan dan Perilaku Kesehatan. Rineka Cipta, Jakarta.

Siregar. C.J.P. 2003. Farmasi Rumah Sakit Teori \& Penerapan. EGC, Jakarta.

Sugiyono. 2011. Metode Penelitian Kuantitatif, Kualitatif dan $R \& D$. Alfa Beta, Bandung.

Sulo,R.H.,Hartono,E.,Oetari,R.A. 2019. Analisis Pengaruh Kualitas Pelayanan Terhadap Kepuasan Pasien Rawat Jalan Di Instalasi Farmasi Rumah Sakit X Kota Surakarta. Jurnal Ilmiah manuntung. 5(1):81-90. 